\title{
EI marketing político 3.0 y el uso de la posverdad por parte de los partidos políticos en España
}

O marketing político 3.0 e o uso da pós-verdade pelos partidos políticos na Espanha

Political marketing 3.0 and the use of political power by political parties in Spain

\author{
R. Rebeca Cordero Verdugo \\ raquelrebeca.cordero@universidadeuropea.es \\ Universidad Europea de Madrid - España \\ https://orcid.org/0000-0002-1087-2094
}

Laura Reyero Simón

laurareyero@gmail.com

ESCP Business School y Universidad Europea de Madrid - España https://orcid.org/0000-0003-0433-3518

\begin{abstract}
RESUMEN
Este artículo nos muestra la evolución del marketing político. Desde el modelo 1.0, hasta la consolidación del nuevo paradigma 3.0. Llegando a quedar demostrada la perversión del modelo del markteing 3.0 debido al uso que los partidos políticos hacen de las narrativas presentes en la posverdad como una forma de aumentar su fidelización con el ciudadano, luego electorado, mediante la construcción de mensajes hiperbólicos y segmentados. Se partió del siguiente objetivo general: analizar si la consolidación del modelo marketing político 3.0 y su uso por parte de los partidos políticos españoles, se vio afectado por la utilización de narrativas de propias de la posverdad. La metodología de trabajo utilizada fue la cualitativa y analítica comparativa. Se hicieron uso de los siguientes instrumentos: la observación directa, las entrevistas, el panel de expertos y la revisión documental. Las conclusiones alcanzadas, así como el trabajo que aquí se presenta, es el resultado de dos investigaciones complementarias: La aplicación del marketing político 3.0. El caso del éxito de Podemos y Ciudadanos en las elecciones de 2014,2015 y 2016 y Marketing político 3.0: Como Podemos, Ciudadanos y Vox han cambiado las reglas del juego. Los resultados que pudimos extraer se resumen en: (1) Todos los partidos políticos españoles han incorporado de la posverdad a sus discursos favoreciendo: polarización, radicalización y enemigos invisibles. (2) La intensidad y el volumen de los mensajes condicionados por los partidos políticos españoles dependen del público que quieran captar. (3) La co-creación y la construcción de mensajes ilusionantes, ha sido sustituido por una construcción distópica centrada en la "búsqueda del culpable".
\end{abstract}

Palabras clave / Descriptores: Marketing 3.0, Posverdad, Partidos Políticos, Radicalización

\section{RESUMO}

Este artigo nos mostra a evolução do marketing político. Do modelo 1.0, à consolidação do novo paradigma 3.0. A perversão do modelo markteing 3.0 tem sido demonstrada devido ao uso que os partidos políticos fazem das narrativas presentes na pós-verdade como forma de aumentar sua lealdade com o cidadão, depois o eleitorado, por meio da construção de mensagens hiperbólicas e segmentadas. O ponto de partida foi o seguinte objetivo geral: analisar se a consolidação do modelo de marketing político 3.0 e sua utilização pelos partidos políticos espanhóis foi afetada pelo uso de narrativas pós-verdade. A metodologia de trabalho utilizada foi qualitativa e analítica comparativa. Foram utilizados os seguintes instrumentos: observação direta, entrevistas, painel de especialistas e revisão documental. As conclusões alcançadas, assim como o trabalho aqui apresentado, são o resultado de duas investigações complementares: La aplicación del marketing político 3.0. El caso del éxito de Podemos y Ciudadanos en las elecciones de 2014,2015 y 2016 y Marketing político 3.0: Como Podemos, Ciudadanos y Vox han cambiado las reglas del juego. Os resultados que pudemos extrair resumem-se em: (1) Todos os partidos políticos espanhóis incorporaram a pós-verdade em seus discursos, favorecendo: polarização, radicalização e inimigos invisíveis. (2) A intensidade e o volume das mensagens condicionadas pelos partidos políticos espanhóis dependem do público que desejam captar. (3) A co-criação e construção de mensagens emocionantes foi substituída por uma construção distópica centrada na "busca do culpado".

Palavras-chave: Marketing 3.0, Pós-verdade, Partidos Políticos, Radicalização.

\section{ABSTRACT}


This article shows us the evolution of political marketing. From the 1.0 model, to the consolidation of the new 3.0 paradigm. The perversion of the markteing 3.0 model has been demonstrated due to the use that political parties make of the narratives present in post-truth as a way to increase their loyalty with the citizen, then the electorate, through the construction of hyperbolic and segmented messages. The starting point was the following general objective: to analyze whether the consolidation of the political marketing 3.0 model and its use by Spanish political parties was affected by the use of post-truth narratives. The work methodology used was qualitative and comparative analytical. The following instruments were used: direct observation, interviews, panel of experts and documentary review. The conclusions reached, as well as the work presented here, is the result of two complementary investigations: La aplicación del marketing político 3.0. El caso del éxito de Podemos y Ciudadanos en las elecciones de 2014,2015 y 2016 y Marketing político 3.0: Como Podemos, Ciudadanos y Vox han cambiado las reglas del juego. The results that we were able to extract are summarized in: (1) All Spanish political parties have incorporated post-truth into their speeches, favoring: polarization, radicalization and invisible enemies. (2) The intensity and volume of the messages conditioned by the Spanish political parties depend on the audience they want to capture. (3) The co-creation and construction of exciting messages has been replaced by a dystopian construction centered on the "search for the culprit".

Keywords: Marketing 3.0, Post-truth, Political Parties, Radicalization.

\section{INTRODUCCIÓN}

El presente trabajo trata de demostrar qué ha sucedido tras la consolidación del modelo de marketing político 3.0. ¿Ha existido realmente una consolidación?, es decir, ¿podemos asumir que todos los partidos políticos españoles hacen uso de las estrategias del marketing político 3.0?

De ser así estamos ante uno de los cambios más significativo y acelerado del marketing político a nivel occidental. Ya que durante décadas los partidos políticos únicamente han acompañado sus campañas electorales de estrategias propias del marketing 1.0. Ahora, en poco menos de cinco años, partidos de larga tradición electoral y partidos de nueva creación comparten estrategias políticas.

Pero éramos conscientes que no debíamos quedarnos aquí porque una vez corroborásemos que la consolidación del modelo era un hecho, teníamos que saber si se había producido conforme a los criterios de creación, en los relativo al uso de las herramientas, o por el contrario las narrativas de las posverdades habían sido adoptadas por los partidos generando una perversión del modelo con otros impactos a nivel social.

Partimos del siguiente objetivo general: analizar si la consolidación del modelo marketing político 3.0 y su uso por parte de los partidos políticos españoles, se vio afectado por la utilización de narrativas de propias de la posverdad.

Y lo articulamos en los siguientes objetivos específicos: (1) Conocer cómo ha evolucionado el marketing político hasta el nuevo paradigma del marketing político 3.0 presente en España con la llegada de Podemos y Ciudadanos a las instituciones españolas. (2) Demostrar la consolidación del marketing político 3.0 con entrada de Vox en el parlamento, y la adopción del modelo por el resto de partidos tradicionales. (3) Identificar si ha influido la posverdad en las narrativas partidistas a la vez que se consolidaba el modelo.

Para posteriormente llegar a verificar las siguientes hipótesis: (1) Los partidos políticos de nueva creación: Podemos, Ciudadanos y Vox, consolidaron el modelo del marketing 3.0 en cuanto que eran los nativos del modelo y según fueron creciendo y afianzando su presencia a nivel institucional se dieron cuenta gran poder que tenían esas herramientas para seguir conectando con sus seguidores, lo que genero un cambio en la forma de hacer política en España. (2) Los partidos políticos de vieja tradición, asumieron que era necesario hacer uso de las estrategias del marketing 3.0 para conectar con un público que no podría ser filiado de otro modo, lo que les llevó a sumar más estrategias de marketing a las habituales. (3) La consolidación del modelo marketing político 3.0 ha llegado de la mano de narrativas propias de la posverdad que no han generado la 
construcción de un nuevo modelo sino perversión del 3.0, en cuanto que usa sus mismas herramientas, pero de manera distópica para la construcción de enemigos.

Sin duda, resulta necesario realizar estudios sobre las estrategias llevadas a cabo por los partidos para aumentar y mantener sus adeptos, por las enormes consecuencias que de un mal uso de las mismas se puede devenir a nivel social: polarización, radicalización, estigmatización de minorías, y revueltas.

La investigación ha sido desarrollada en tres fases. Fase 1 "El origen", centrada en demostrar la existencia de un nuevo paradigma el del marketing político 3.0 utilizado por Podemos y Ciudadanos para conseguir su éxito electoral. De esta investigación resultó una tesis doctoral bajo el nombre de: "La aplicación del marketing político 3.0. El caso del éxito de Podemos y Ciudadanos en las elecciones de 2014,2015 y 2016". Fase 2 "La consolidación”, aplicada al caso de VOX para verificar la consolidación del nuevo paradigma de marketing político 3.0 del que resultó la publicación del libro: "Marketing político 3.0: Como Podemos, Ciudadanos y Vox han cambiado las reglas del juego" y una tercera "La perversión", desarrollada en plena pandemia, centrada en comprobar el uso que se estaba dando a las herramientas de marketing político 3.0, por los partidos. Una vez realizadas las tres fases extraíamos las conclusiones que se pondrán manifiesto al final del artículo.

En resumen, esto será lo que serán en cada uno de los apartados de artículo:

1. Capítulo 2: desarrollaremos un breve marco teórico en el que evidenciamos la evolución y los elementos que participan en los diferentes tipos de marketing políticos existentes: 1.0, 2.0 y 3.0, así como la consolidación de este último.

2. Capítulo 3: explicaremos la metodología utilizada en el trabajo de campo, cualitativa y analítica comparativa.

3. Capítulo 4: nos centraremos en los resultados obtenidos y en verificación de las hipótesis. Presentaremos datos obtenidos en el trabajo de campo.

4. Capítulo 5: concluiremos que se han producido tres realidades claramente definidas: (1) Todos los partidos políticos españoles han incorporado de la posverdad a sus discursos favoreciendo: polarización, radicalización y enemigos invisibles. (2) La intensidad y el volumen de los mensajes condicionados por los partidos políticos españoles dependen del público que quieran captar. (3) La co-creación y la construcción de mensajes ilusionantes, ha sido sustituido por una construcción distópica centrada en la "búsqueda del culpable".

\section{LA EVOLUCIÓN DEL MARKETING POLÍTICO Y LA CONSOLIDACIÓN DEL MODELO 3.0}

\subsection{Marketing político: su evolución hasta la creación del marketing político 3.0}

El desarrollo del marketing viene determinado por una constante reconsideración del concepto, así como de sus objetivos y de su ámbito de aplicación. Además, está directamente condicionado por los cambios tecnológicos y sociales de cada momento.

"El marketing evoluciona al ritmo que le marcan los cambios sociales y tecnológicos, su transformación depende de su adaptación al cambio", como ya advirtió Dvoskin (2004, p. 22). La aparición de nuevas tecnologías como la radio, la televisión, Internet y los teléfonos móviles, entre otras, conlleva el enriquecimiento de esta disciplina y la conduce hasta el paradigma actual: el marketing 3.0. 
En paralelo el marketing, como ciencia y como práctica, va ampliando su campo de aplicación, además de aplicarse a la venta de productos se reconoce la bondad de su aplicación a los mercados de servicios, y a mercados industriales y mientras el marketing evoluciona del 1.0 al 2.0. Kotler (1992) escribe Marketing social. Estrategias para cambiar la conducta pública, en el que por primera vez se estudia y se enuncia como el marketing debe ser aplicado en un nuevo ámbito, el social. Situamos al marketing político como una rama del social. Esta amplitud en el enfoque llevó a reconocer la aplicación del marketing también en los mercados de servicios e industriales.

Aunque, como siempre, la aplicación es anterior a la conceptualización académica. La práctica del marketing político nace, según Maarek (2009), en 1952, año de las elecciones de Eisenhower frente a Stevenson, relata Mauser (1983). Comparte semejanzas con el marketing general 1.0, ambos son verticales y requieren elevadas inversiones, creando mercados con altas barreras de entrada.

En estos años se crean herramientas y estrategias que a día de hoy siguen siendo distintivas e imprescindibles en el marketing político, como los debates, mítines, comunicación y publicidad defensivas, y la liturgia de la pegada de los primeros carteles.

El marketing político 2.0 surge en el año 2007 con las primarias de Barack Obama, contra Hillary Clinton. En estos años las tecnologías de la información y comunicación, especialmente Internet, representan una oportunidad para acercar las instituciones a los ciudadanos, facilitando la interacción entre ellas (Arroyo, 2012), ya sea de manera colectiva o individualizada (Caldevilla, 2009). Es un medio que puede ser empleado tanto por partidos como organizaciones o ciudadanos (Anduiza et al., 2010). Y a través de estas herramientas se da paso a nuevas formas de democracia directa, o al menos, se consigue una mayor legitimidad de las instituciones democráticas existentes (Pinchart y González, 2013).

Internet, y otras nuevas tecnologías asociadas, son los facilitadores de la aparición de las bases sobre las que se construye el marketing político 2.0, este ya ampliamente diferenciado del marketing general 2.0. Aparece la co-creación, que en el ámbito político se produce gracias a los voluntarios que se convierten en prosumidores ${ }^{1}$ que crean y difunden los mensajes.

El entorno 2.0 es muy visual, por eso la videopolítica, nacida en las redes sociales, desempeña un papel protagonista y constituye una nueva forma de hacer política respecto al visto anteriormente. El ciberactivismo marcará este nuevo entorno. Obama es un cibercandidato maestro en el manejo de la estrategia del storytelling ${ }^{2}$ (Cárdenas, 2013).

Sin duda, la aparición del Big Data ${ }^{3}$ y el politament ${ }^{4}$ también favorecieron el impulso del marketing político 2.0 .

El Big Data que permite llegar a niveles de microsegmentación jamás imaginados anteriormente. El Big Data, unido al complejo entramado de redes sociales, posibilita lanzar mensajes casi individualizados. El progreso ayuda a microsegmentar sin incurrir en altos costes, a través de técnicas como el posicionamiento web (SEO) o la publicidad digital (SEM).

\footnotetext{
${ }^{1}$ Prosumidor es el consumidor que se convierte en productor, aunque la idea de que las personas que utilizan un producto deben contribuir a su diseño y producción no parece nueva, ya que en la historia de la invención se han dado muchos casos de creatividad impulsada por el usuario.

${ }^{2}$ Storytelling es un término usado en el contexto de la web 2.0, de uso generalizado, aunque no recogido por la RAE, que se refiere a la capacidad que tiene un contenido de comunicación de reproducirse, multiplicarse y expandirse por la red.

${ }^{3}$ Big Data es un término inglés que hace referencia a las ingentes cantidades de datos, datos masivos o datos a gran escala que las aplicaciones informáticas tradicionales del procesamiento de datos no son suficientes para tratar con ellos y también hace referencia a los procedimientos usados para encontrar patrones repetitivos dentro de esos.

4 Politainmet es un término inglés que hace referencia al espectáculo político en televisión. Cada vez más los candidatos, con el objetivo de ganar notoriedad y cercanía con los ciudadanos, participan en programas de entretenimiento y se prestan a dar espectáculo. También se refiere al infotainment asociado a la actividad política.
} 
Por otro lado, el politament irrumpe en el escenario del marketing político cambiando las estrategias de comunicación, ya que simplifica el mensaje político para que se adapte mejor a los medios audiovisuales, fundamentalmente YouTube y así captar la atención de los diferentes segmentos o microsegmentos objetivo.

La aparición del nuevo paradigma del marketing político 3.0 nace en España a partir del movimiento del 15-M, también llamado "movimiento de los indignados”. Se materializó en diferentes manifestaciones y varios días de asentamientos en la Puerta del Sol de Madrid que comenzaron el 15 de mayo de 2011. Este movimiento social tuvo como objetivo provocar un cambio social que implicase, entre otras cuestiones, un modelo de democracia más representativas y un aumento de las mejoras sociales. El 15-M se crea gracias a la tecnopolítica y el ciberactivismo protagonizado por los millennials. Su materialización en partido político se da años después con el surgimiento de Podemos, un nuevo partido que llegó a las instituciones a romper el pseudo bipartidismo imperante hasta el momento.

Podemos y Ciudadanos son partidos creados por millennials en un entorno multipantalla, liderados por cibercandidatos que han cambiado la forma de hablar y de relacionarse con sus votantes, con los que dialogan constantemente y con los que co-crean. Partidos que dialogan sobre valores y que se financian con crowdfunding. Todos ellos pilares del marketing 3.0. (Reyero, 2017).

En el año 2014 Podemos irrumpió en el entorno político con una nueva estrategia de marketing. Ciudadanos se incorporó un poco más tarde, cuando saltó a la política fuera de Cataluña ${ }^{5}$ Y unos años más tarde, otro partido consolida y perfecciona el marketing político 3.0, VOX $^{6}$. Tres partidos muy diferentes en cuanto a ideología, imagen, y atributos, pero que comparten las mismas bases de creación, estrategias y tácticas y entre los tres, y sin ser conscientes, crean, evolucionan y consolidad el marketing político 3.0 que, transforma, renueva y perfecciona el marketing político 2.0 creado por Obama unos años antes y que nunca se había aplicado en España, ya que los partidos políticos sólo habían tenido estrategias 1.0 a las que han incorporado herramientas digitales.
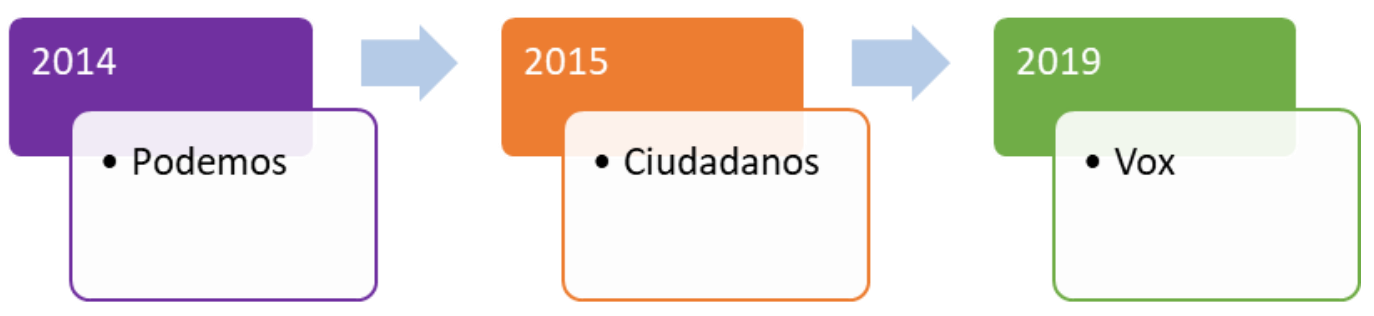

Figura 1. Partidos políticos 3.0 en España. Año de incorporación a las instituciones nacionales o internacionales. Elaboración propia, 2021.

En las primeras campañas de Podemos y Ciudadanos, destaca el protagonismo de la comunidad, que conduce a la co-creación y al crowdfunding. Podemos es un partido co-creado por sus círculos, que también co-crean los programas electorales. En Ciudadanos las bases co-crean los mensajes y los difunden, pero no el programa electoral, aunque se tiene en cuenta su opinión, se permite una base de co-creación, la versión final es realizada por expertos. Esta comunidad se convierte a sus integrantes en prosumidores, igual que hizo Obama.

\footnotetext{
${ }^{5}$ Ciudadanos nació como partido político en el año 2006, pero solo hacía campaña y se presentaba en las elecciones de la Comunidad Autónoma de Cataluña. No salto a la política nacional hasta el año 2015.

${ }^{6}$ La presencia de VOX en las instituciones autonómicas remonta a 2018.
} 
El crowdfunding puede ser una táctica independiente o puede estar integrado en una estrategia de gamificación, con el objetivo final de fidelizar, como hizo Ciudadanos en una excelente campaña en la que estaba ligado a un plan de fidelización.

Los nuevos líderes son millennials, los equipos son millennials, los voluntarios son millennials, el target es millennial, si no de edad si de corazón. Hay tres características básicas de los millennials que inciden especialmente en este entorno: rechazo al pasado, a sus marcas, y a su modelo económico social. Están convencidos de poder cambiar la realidad en la que viven. Son nativos digitales. Desde que tienen uso de razón han tenido acceso a un teléfono móvil.

El acceso multipantalla, básico a la hora de establecer las estrategias online, es una base de este paradigma.

Estamos ante la llegada de la tecnopolítica. Sin ella nunca habría existido el 15-M, es decir, no habría existido el marketing político 3.0. La tecnopolítica facilita a los millennials poder alcanzar sus aspiraciones de cambio.

Tal y como pasó en el marketing político 2.0 el nuevo paradigma no anula al anterior, simplemente lo agranda y evoluciona, según afirma Kotler (2012). Muchas herramientas, como los mítines, los debates, la publicidad y el apoyo de la prensa creadas en los entornos 1.0 y 2.0 siguen siendo protagonistas del marketing político 3.0

Un paradigma triunfa cuando es asumido por gran parte de los participantes de un mercado. En España el marketing político 2.0 no triunfó porque no fue asumido por ningún partido. Se limitaron a usar las redes sociales como canal de comunicación, pero no hubo diálogo, ni cibercandidatos.

En cambio, sí hemos observado como la nueva forma de hacer marketing político de Podemos y Ciudadanos ha influido en los dos partidos tradicionales más relevantes. Tanto PP como PSOE tuvieron que cambiar sus estrategias y tácticas de campaña para amoldarse al nuevo paradigma, a la nueva forma de diseñar los planes de marketing. Han tenido que saltar del marketing 1.0 al 3.0 en menos de un año. "Y esta nueva forma de hacer ha calado en los partidos tradicionales, que, en las dos últimas campañas, diciembre del 2015 y la de junio del 2016, han incorporado la nueva forma de operar: el marketing político 3.0” (Reyero, 2017).

\subsection{Marketing político 3.0. VOX lo consolida}

En una segunda fase nuestra investigación, ampliamos el estudio a las elecciones para el Parlamento de Andalucía (2018) en las que VOX obtuvo 12 diputados y las generales del 2019 en las que obtuvo 3.656 .979 votos que le proporcionaron 52 diputados y pudimos confirmar que VOX además de trabajar en el marco del marketing político 3.0, lo había perfeccionado y consolidado

El marketing 3.0 se basa en la comunidad, en la que se desarrolla la co-creación y la economía colaborativa, dentro de la que integramos el crowdfunding. También se basa en la figura del prosumidor. VOX se ha construido usando las bases del marketing político 3.0: sus voluntarios son prosumidores que co-crean el plan de comunicación. Vimos que la co-creación más extrema era la de Podemos, con sus círculos, y que la de VOX se asemeja a la de Ciudadanos.

Para animar esta co-creación tanto VOX como Ciudadanos han usado estrategias de gamificación, tan usadas en entornos diferentes al político. 
Las redes sociales se mueven gracias a los voluntarios, afiliados o no al partido, que viralizan los mensajes y hacen memes ${ }^{7}$. Nos decía Fernando Paz -En torno a VOX se ha movilizado mucha gente, incluso no afiliados, y eso ha llevado a un gran entusiasmo. Gente, no del partido, que han organizado cenas, actos y demás. (Cordero y Reyero, 2020, p. 248)

En cuanto al crowdfounding dan un paso más y proponen que todos los partidos se financien solo con cuotas, donaciones y crowfounding. En el punto 82 del documento que servirá de base para la elaboración del programa electoral de VOX a las elecciones andaluzas, anunciaban su intención de retirar todas las subvenciones públicas a las estructuras políticas y sindicales. Y siguen con este mensaje a día de hoy.

En la página web de VOX se podía seguir en directo el crecimiento de las donaciones, era espectacular. VOX tiene perfectamente organizado el crowdfunding, han desarrollado una fórmula rápida y efectiva. Mandan un correo electrónico con un mensaje que dice: "¿Nos ayudas?". Ese mensaje se propaga por WhatsApp. Usan mensajes tan potentes y como: "No quieren que estemos en el proceso contra los secesionistas. Nos intentan echar con una desproporcionada fianza; ¿nos ayudas?". Tienen un sistema por el que en menos de 2 horas pueden llegar al $80 \%$ de sus bases con sus peticiones.

También comparte el protagonismo de los millennials, que son nativos digitales y gracias a ellos ha aparecido la segunda base específica del marketing político 3.0, la multipantalla.

Casi todos los líderes de VOX son millennials, al igual que su target. Recordemos el mitin en la discoteca Barceló de Madrid y sus actividades en colegios mayores y otros entornos millennials. Su estilo de comunicación tiene una estética millennial, con los memes a la cabeza. Si bien, la figura de millennials de corazón también está presente, sumándose al partido cada vez más gente de edad avanzada. Según Mariscal "VOX está cambiando las reglas en cuanto que ya no son los padres los que dicen que votar a los hijos, sino que estos millennials a los que ha llegado el mensaje de VOX están convenciendo a sus padres y abuelos para que ellos también voten a VOX" (Cordero y Reyero, 2020, p. 240).

En cuanto a la multipantalla VOX ha ido un paso más allá de Podemos y Ciudadanos. Cuando ellos crearon el marketing político 3.0 la multipantalla no eliminó a la televisión. VOX se ha creado y ha crecido sin la televisión, sólo con las pantallas del teléfono y de la tablets y ordenadores.

La tecnopolítica, por tanto, también aplica a VOX ya que permite a los millennials, de edad y de corazón, canalizar sus aspiraciones de cambio.

Y tal como le ocurrió al marketing político 2.0 el nuevo paradigma no anula al anterior, lo agranda y evoluciona. VOX ha seguido usando herramientas del marketing político 2.0 y 1.0, aunque con menor intensidad de lo que hicieron Podemos y Ciudadanos, e incluso ha abandonado algunas.

VOX ha demostrado que se puede crear y hacer crecer un partido sin el apoyo de la prensa.

Los tres partidos tienen ideología, mensajes y tonos de comunicación muy diferentes. En cuanto al tono y estilo de comunicación Ciudadanos fue a Obama, lo que VOX es a Trump. Pero ambos tonos caben dentro del marketing político 3.0

\footnotetext{
${ }^{7}$ El término meme de internet se usa para describir una idea, concepto, situación, expresión o pensamiento, manifestado en cualquier tipo de medio virtual, comic, vídeo, audio, textos, imágenes y todo tipo de construcción multimedia, que se replica mediante internet de persona a persona hasta alcanzar una amplia difusión.
} 
VOX tiene un estilo de comunicación único, que marca una diferencia ha creado estilo épico $^{8}$ reforzado con grandes gestos o gestos contundentes (llegar a Gibraltar a nado para poner una bandera de España, Abascal a caballo por el campo Andaluz, o hacer un mitin en Vistalegre, lugar emblemático de Podemos, entre otros).

VOX también ha tenido grandes gestos de sentido del humor no sólo han usado contra sus adversarios políticos, también han sabido reírse de sí mismos y en sus cuentas hemos encontrado muchos memes en este sentido. Hasta esta fecha sólo el PP se había atrevido a reírse de sí mismos, lo hicieron en la campaña del 2015 con comerciales como Hispter, Moteros o Gatos.

VOX ha utilizado y consolidado el marketing político 3.0, en algunos pasos incluso perfeccionando el uso de algunos instrumentos, como la videopolítica y el extraordinario manejo de las multipantallas.

\section{PROCEDIMIENTOS METODOLOGICOS}

La investigación ha sido desarrollada en tres fases. Fase 1 "El origen", centrada en demostrar la existencia de un nuevo paradigma el del marketing político 3.0 utilizado por Podemos y Ciudadanos para conseguir su éxito electoral. De esta investigación resultó una tesis doctoral bajo el nombre de: "La aplicación del marketing político 3.0. El caso del éxito de Podemos y Ciudadanos en las elecciones de 2014,2015 y 2016". Fase 2 "La consolidación”, aplicada al caso de VOX para verificar la consolidación del nuevo paradigma de marketing político 3.0 del que resultó la publicación del libro: "Marketing político 3.0: Como Podemos, Ciudadanos y Vox han cambiado las reglas del juego" y una tercera "La perversión” desarrollada en plena pandemia para comprobar el uso que se estaba dando a las herramientas de marketing político 3.0, por los partidos.

En las dos primeras fases se utilizaron técnicas cualitativas tales como: etnografía, entrevistas en profundidad y estudio Delphi. Dejándose para la tercera parte el estudio analítico comparativo apoyado en resultados anteriores obtenidos por nosotros en fase 1 y 2 , en referencias bibliográficas recientes. El uso de esta metodología está justificado en cuanto que identifica de manera sensible aquellos aspectos vinculados al marketing político 3.0 con una doble vertiente: el marketing como disciplina y la ciencia política (Reyero, 2016).

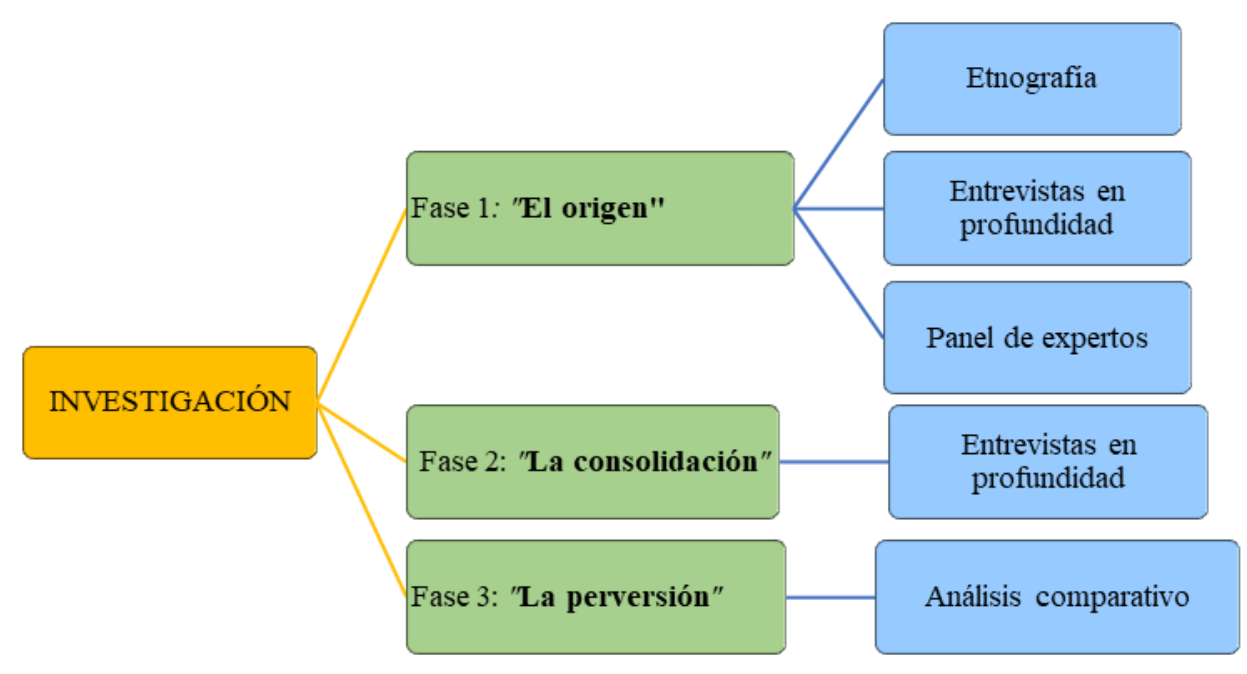

\footnotetext{
${ }^{8}$ El género épico es uno de los géneros que permiten narrar hazañas y gestos heroicos que pueden ser reales o ficticios y sus hazañas suelen ser magnánimas, las cuales permiten guardar o formar una leyenda épica y que los personajes trasciendan posteriormente. Proviene de la palabra epos, que en griego significa 'narración'. La poesía épica es la que narra las hazañas de héroes históricos o legendarios. Posee las siguientes características: relata sucesos legendarios o históricos de importancia nacional o universal.
} 
Figura 2. Estructura compleja de trabajo. Elaboración propia, 2021.

\subsection{Etnografía / Observación directa}

El acompañamiento a Podemos y a Ciudadanos se hizo adoptando la figura de apoderado en las elecciones municipales de 2015 y las generales de 2015 y 2016 colaborando como voluntario con sus campañas electorales, asistiendo a las reuniones de ambos partidos y sus cursos de formación en sus sedes centrales y locales, suscribiéndonos a sus correos informativos e interactuando en sus redes sociales. Lo que se acompañó con un seguimiento de las informaciones referidas a estos que salían en los medios de comunicación.

Todo el trabajo etnográfico se hizo siguiendo los códigos éticos de la AoIR $^{9}, \operatorname{ISA}^{10}$, ASA $^{11}$ y AAA $^{12}$ cumpliendo con la ética investigadora. En todo momento los partidos políticos y sus miembros fueron conscientes que la encargada de la etnografía era una investigadora. Así se presentó a los diferentes partidos pidiendo que la dejasen participar de ello. Todas las interactuaciones realizadas por ella con miembros de los partidos se hicieron bajo la premisa de que estaba investigando sobre sus formas de realizar marketing político.

La etnografía fue la técnica que estuvo presente a lo largo de todo el trabajo de campo dado que la información resultante de ella sirvió para plantear las entrevistas en profundidad y el panel de expertos. Además, las respuestas obtenidas de las entrevistas y del papel de expertos volvían a ser objeto de análisis en la etnografía. Fueron 100 horas las destinadas al trabajo etnográfico.

Basándonos en las recomendaciones de Angrosino (2012), la observación directa ser realizó de manera desigual a lo largo de las tres fases de investigación. En la primera fase fue directa, multisituada ${ }^{13}$ y continuada en el tiempo. En la segunda fase fue directa, unifocal ${ }^{14}$ y limitada en el tiempo 20 horas. Y en la tercera fase fue indirecta y tuvo un objetivo puramente reflexivo por eso no se indica como metodología principal.

\subsection{Entrevistas en profundidad}

El uso de las entrevistas ${ }^{15}$ abiertas en profundidad en formato río se realizaron en las dos primeras fases, realizándose 21 entrevistas en la primera y 3 en la segunda. La utilidad de este tipo de entrevistas reside en la calidad de la información a obtener y en la posibilidad de adaptar el guion al argumento de entrevistado.

En la entrevista en profundidad el entrevistador desea obtener información sobre determinado problema y a partir de él establece una lista de temas, en relación con los que se

\footnotetext{
${ }^{9}$ Toma de decisiones ética en internet de la Association of Internet Researchers.

${ }^{10}$ Código ético de la International Sociological Asssociation

${ }^{11}$ Código ético de la Association of Social Anthropology británica.

${ }^{12}$ Código ético de la American Anthropological Association.

${ }^{13}$ Es multisituada, en cuanto que la etnografía se realiza en diferentes espacios físicos y digitales interrelacionados.

${ }^{14}$ Es unifocal, porque en la segunda fase de la investigación únicamente se puso el foco una única dimensión. Vox como generador de información de la red y el crecimiento de seguidores.

${ }^{15}$ El guion de entrevista puede consultarse en: Reyero, L. (2017). La aplicación del Marketing Político 3.0. El caso del éxito de podemos y ciudadanos en las elecciones de 2014,2015 y 2016 [Tesis doctoral, Programa de Doctorado en Economía y Empresa, Universidad Europea de Madrid, España].
} 
focaliza la entrevista, quedando esta, a la libre discreción del entrevistador, quién podrá sondear razones y motivos, pero sin sujetarse a una estructura formalizada de antemano (...) tienen ciertas ideas, más o menos fundadas, y desean profundizar en ellas hasta hallar explicaciones convincentes. Puede, incluso, que en ocasiones sólo desee conocer cómo otros -los participantes en la situación o contexto analizado-ven el problema. (Rodríguez, et al., 1996, p. 168)

Los entrevistados eran expertos en comunicación política, estrategias de márquetin político y campañas de marketing. Que habían estado al frente de las campañas electorales de los partidos con más larga tradición electoral en el país (PSOE y PP) y de los nuevos partidos (Podemos, Ciudadanos y Vox). Los entrevistados fueron seleccionados siguiendo las características de Taylor y Bogdan (1987): dinámica, aleatoria, intencionada y deliberada.

\subsection{Estudio Delphi}

Esta técnica fue diseñada por la Rand Corporation ${ }^{16}$ a partir del año 1948. Originalmente fue utilizada para tratar problemas estratégicos y militares, con el ánimo de mejorar la efectividad de las opiniones de expertos sobre temas bélicos.

Los estudios Delphi buscan el consenso de expertos. Todos comparten lo que el resto han opinado de forma confidencial, esto conduce a un proceso que les hace reflexionar sobre sus puntos de vista iniciales. Este método pretende extraer y maximizar las ventajas que presentan las técnicas basadas en grupos de expertos y minimizar sus inconvenientes. Se aprovechan las sinergias del trabajo en grupo, eliminando las interminables discusiones al no haber interacciones entre los miembros del grupo. Sólo el organizador del estudio sabe quiénes son los expertos, requisito imprescindible para garantizar el éxito del método y fomentar la creatividad de los participantes.

El Delphi trabaja en base a procesos repetitivos. Se elabora un cuestionario que debe ser respondido por los expertos. Este cuestionario se reenvía, informando de las respuestas del grupo, para que cada experto confirme o cambie sus primeras respuestas.

Hemos realizado esta investigación para entender como se ha aplicado el marketing político 2.0 en España durante los años que coinciden con la aplicación del marketing político 2.0 en Estados Unidos.

Y para ello hemos montado, el que, según nuestras comprobaciones, es el primer, y de momento único, panel de expertos en marketing político en España. Un panel con 25 especialistas de reconocido prestigio en este ámbito. Expertos del ámbito académico, responsables de campañas electorales y diversos consultores de marketing político, tanto generalistas como especializados en alguna herramienta concreta (Cordero et al, 2017).

\footnotetext{
${ }^{16}$ Compañía creada en 1946 por las Fuerzas Aéreas de los EE.UU. para dar continuidad a la colaboración entre científicos universitarios y jefes militares, iniciada durante la Segunda Guerra Mundial. Dentro de la denominada Investigación Operativa.
} 


\subsection{Analítico comparativo}

Con el fin de facilitar la comprensión temporal hemos elaborado el siguiente gráfico que, sintéticamente, recoge los ciclos y las diversas técnicas utilizadas en la investigación durante casi nueve años.

En la tercera fase de la investigación nos decidimos por utilizar el método analítico descriptivo en cuanto debíamos comprobar el uso que se estaba haciendo de las narrativas de la posverdad por parte los partidos políticos españoles. Lo que comprobamos mediante el uso de diferentes fuentes bibliográficas y la comparación entre partidos.

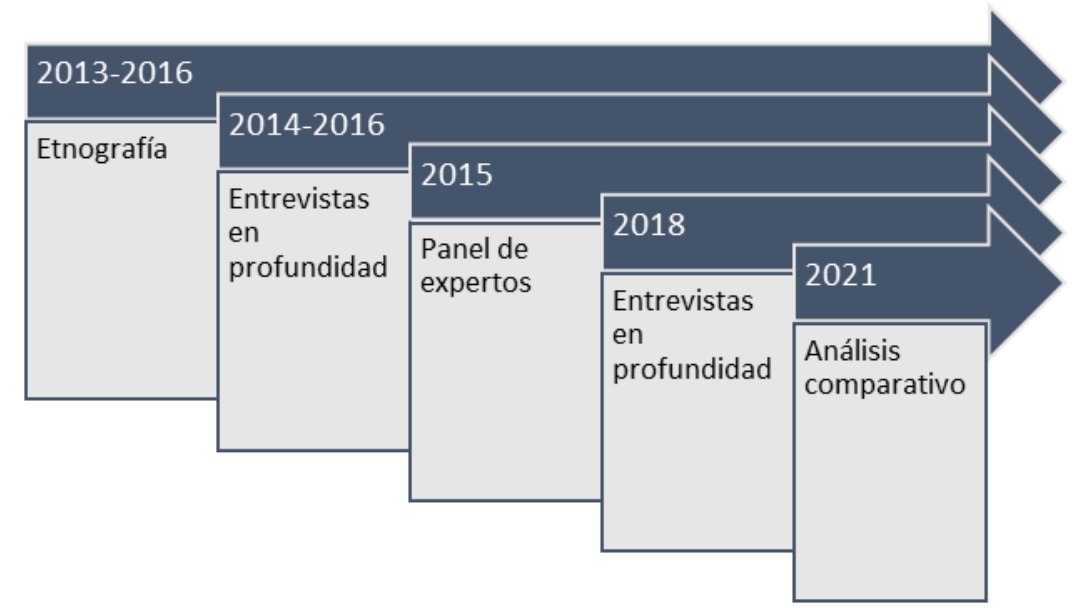

Figura 3. Cronograma metodológico. Elaboración propia, 2021.

\section{RESULTADOS Y DISCUSIÓN}

\subsection{Se confirma la creación del Marketing Político 3.0 por Podemos y Ciudadanos}

Un paradigma triunfa cuando es asumido por gran parte de los concurrentes del entorno. En España el marketing político 2.0 no triunfó porque no fue asumido por ningún partido. Se limitaron a usar las redes sociales como canal de comunicación, pero no hubo diálogo, ni cibercandidatos. Los voluntarios mantuvieron un papel secundario, limitándose a ayudar en los mailings o a llenar actos, entre otras actividades básicas que no aportan un valor añadido significativo.

En cambio, sí hemos observado como la nueva forma de hacer marketing político de Podemos y Ciudadanos ha influido en los dos partidos tradicionales más relevantes. Tanto PP como PSOE han tenido que cambiar sus estrategias y tácticas de campaña para amoldarse al nuevo paradigma, a la nueva forma de diseñar los planes de marketing. Han tenido que saltar del marketing 1.0 al 3.0 en menos de un año.

Si comenzamos por los dos primeros pilares del marketing político 3.0, la comunidad y los voluntarios convertidos en prosumidores, apreciamos que en estos partidos ya ha habido movimientos en este sentido. Hemos comprobado que no solo se han esforzado en incorporar voluntarios a sus campañas digitales para expandir los mensajes, sino que, además, y por primera vez en su historia, PP y PSOE han realizado consultas sobre decisiones políticas a sus afiliados. Entendemos que podría ser un primer paso de cara a una co-creación más intensa.

El PP ha hecho un esfuerzo por integrar a los voluntarios en el desarrollo de las dos últimas campañas electorales. Ha fomentado una participación más activa que en el pasado y no solo en 
actividades online. En el PSOE la movilización a través de sus voluntarios digitales ha sido una obsesión.

En cuanto al acceso multipantalla, ambos partidos lo han asimilado perfectamente.

Por tanto, afirmamos que el marketing político 3.0 está avanzando rápidamente, aunque, como en otros entornos de aplicación del marketing no todos los concurrentes lo aplicarán con la misma intensidad y pericia.

Es un hecho que el nuevo paradigma, el marketing político 3.0, ha triunfado en España. Con mayor o menor rigor y acierto está siendo utilizado por todos los partidos políticos nacionales.

\subsection{Se confirma que VOX usa y consolida el marketing político 3.0}

En una segunda etapa de esta investigación nos decidimos ampliar nuestro estudio a VOX, en cuanto que nuevo partido dentro del escenario político con unas altas posibilidades de obtener representación a nivel nacional, después de sus resultados en Andalucía. Incorporando un exhaustivo análisis de las estrategias y planes que VOX ha usado desde su creación hasta el momento de la precampaña a las elecciones generales de 2019, haciendo especial hincapié en la campaña al Parlamento andaluz de 2018 que ha llevado a VOX a alcanzar un inesperado éxito electoral.

Concluimos como uno a uno VOX se ha construido usando las bases del marketing 3.0: la comunidad y los prosumidores. Sus voluntarios son prosumidores que co-crean el plan de comunicación. Vimos que la co-creación más extrema era la de Podemos, con sus círculos, y que la de VOX se asemeja más a la de Ciudadanos.

Recordemos que el crowdfounding, que parte de la comunidad, está tan asimilado en el ADN de VOX que incluso proponen que todos los partidos se financien solo con cuotas, donaciones y crowfounding, han ido un paso más allá que las otras formaciones políticas.

Además, se han apoyado y han perfeccionado el uso de las bases específicas del marketing político 3.0, siendo la primera el protagonismo de los millennials, Casi todos los líderes de VOX son millennials, una parte importante de su target son milennials de edad o de corazón

En cuanto a la multipantalla VOX ha ido un paso más allá de Podemos y Ciudadanos. VOX se ha creado y ha crecido sin la televisión, sólo con las pantallas del teléfono y de la tablets y ordenadores.

La tecnopolítica, por tanto, también aplica a VOX ya que permite a los millennials, de edad y de corazón, canalizar sus aspiraciones de cambio.

Y tal como le ocurrió al marketing político 2.0 el nuevo paradigma no anula al anterior, lo agranda y evoluciona. VOX ha seguido usando herramientas del marketing político 2.0 y 1.0, aunque con menor intensidad de lo que hicieron Podemos y Ciudadanos, e incluso ha abandonado algunas.

Abascal, Ortega, todos son cibercandidatos, son nativos digitales, no conciben la comunicación sin ser cibercandidadtos.

En VOX también conviven el mundo online y offline. Son un partido creado en las redes y que no ha abandonado la calle. Durante tres años se han recorrido toda España, en encuentros multitudinarios o muy pequeños.

Tres partidos que en sus estrategias tienen grandes similitudes, comenzando por sus nombres. Ninguno de ellos incorpora la palabra partido a su marca. Los tres saben que partido es un término desacreditado. Tres partidos, radicalmente diferentes, pero co-creadores de una nueva 
forma de hacer marketing político, el 3.0, marco de actuación en el que ya están los partidos históricos.

Los partidos 3.0 han pasado de no existir a alcanzar el $46 \%$ de los escaños en pocos años. Los partidos que han creado el marketing político 3.0 y que están marcando el liderazgo en términos de marketing político ya han alcanzado casi el $50 \%$ de la participación de mercado. Aunque nuestro análisis, nuestra investigación, es cualitativa, la última demostración del éxito de este nuevo paradigma es cuantitativa, los escaños obtenidos por VOX al Congreso de los Diputados en las últimas elecciones generales del 10 de noviembre de 2019 fueron 52.

Por tanto, marketing político 3.0 creado y desarrollado por Podemos y Ciudadanos, no solo ha sido imitado por el PP y el PSOE, sino que ha sido evolucionado y perfeccionado por VOX cambiando para siempre el panorama político español, exigiéndoles a los partidos tradicionales, para no perder el lugar que tuvieron garantizado tiempo atrás, adecuarse al modelo 3.0, un modelo ganador.

\subsection{La posverdad como forma de perversión del marketing político 3.0}

"Cuando se escucha el término posverdad, cabe preguntarse si no estamos simplemente ante una manera políticamente correcta de referirnos a la mentira, tal vez a la mentira utilizada en el ámbito político" (González, 2018, p. 212).

Si bien, Aparicio y García (2019) definen la posverdad como una idea, un imaginario, un conjunto de representaciones sociales o sentidos ya incorporados por las audiencias y desde donde son posibles fake news que refieren a esa idea afirmándola o ampliándola.

La posverdad se desarrolla en el contexto del mundo globalizado, en la sociedad de las redes sociales, en el entorno 3.0, ámbito donde las nuevas tecnologías se encuentran con un deseo de cambio social, por eso Moya explica el nacimiento de la posverdad "cómo la mezcla entre el desarrollo de nuevas tecnologías revolucionarias, a la par que un contexto social único basado en ideales democráticos potenciados por un proceso de globalización, han sido los elementos clave de unas nuevas y reconvertidas generaciones que utilizan las redes sociales como un punto de apoyo social, así como una fuente de información sobre la realidad muy relevante" (2018, p. 109). Un contexto en el que se entremezclan los posicionamientos y las ideas sin una fundamentación teórica clara.

Imagen 1. Éxito de las redes sociales para campañas de la posverdad 


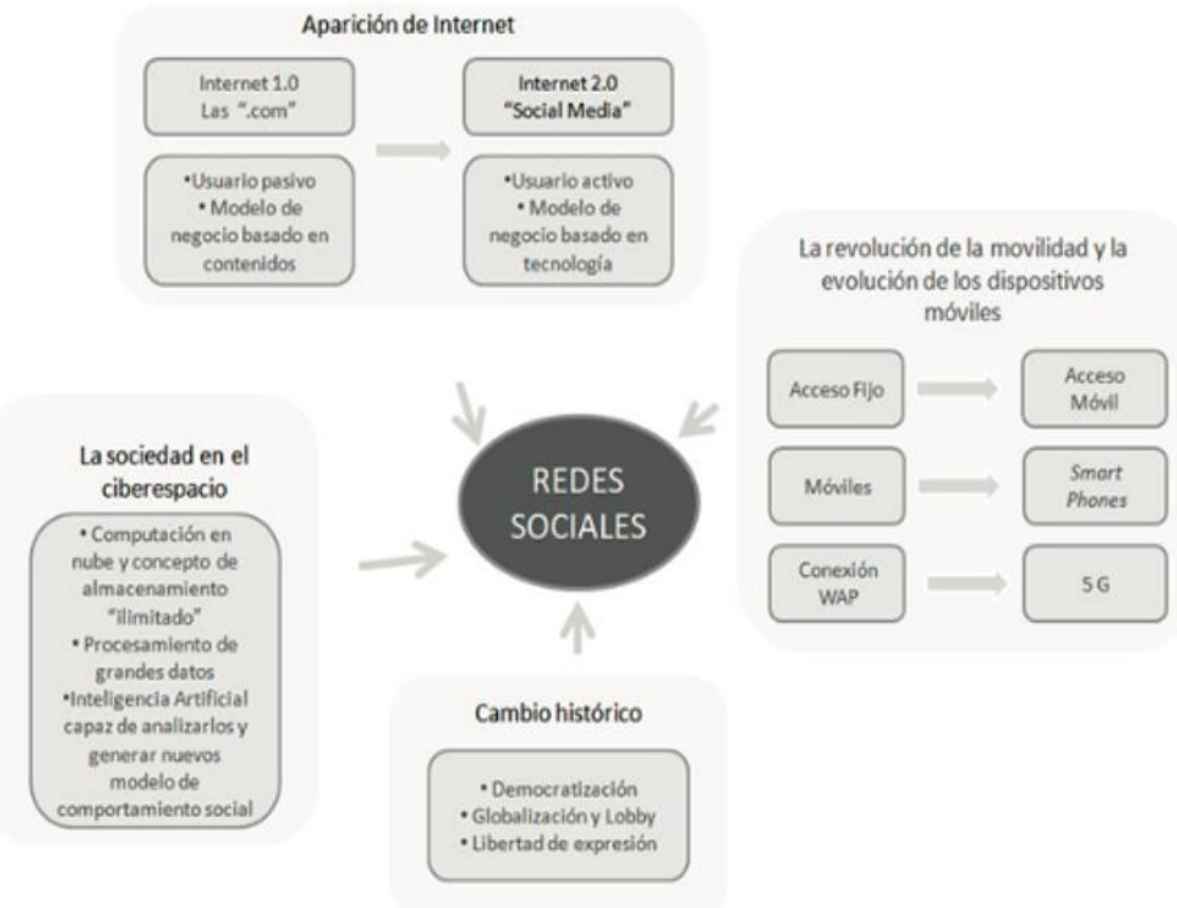

Nota: Extraído de Moya, 2018, p. 109.

Hay innumerables muestras de la relevancia social que ha alcanzado, son miles los artículos académicos y de divulgación sobre este tema, hasta tal punto que, en el año 2016, el Oxford English Dictionaty le dedicó su palabra del año, posverdad, a Trump y al Brexit. Afirmó que el término alude a aquella situación "en la que los hechos objetivos influyen menos en la formación de la opinión pública que las apelaciones a la emoción y a las creencias personales" (OED, 2016).

Un año más tarde, en el 2017, el Diccionario de la Real Academia de la Lengua Española, en su $23^{a}$ edición, reconocía la existencia de este término, definiéndolo como la "distorsión deliberada de una realidad que manipula creencias y emociones con el fin de influir en la opinión pública y en actitudes sociales" (RAE, 2017). Ese mismo año El Collings Dictionary eligió como palabra del año una expresión "casi indisolublemente ligada a la posverdad, fake news, que la define como: -información falsa, a menudo sensacional, difundida bajo el disfraz de noticia-" (RodríguezFerrándiz, 2019, p.4).

La posverdad, las fake news, se producen en todos los ámbitos, aunque en el que más se ha desarrollado y más impacto social ha tenido es en el político y esto es porqué las noticias políticas son divisorias. Incitan a la mitad de los lectores: los que están a favor o en contra del titular. Generando procesos de polarización política.

La posverdad no son noticias completamente falsas. Generalmente se catalogan en tres grupos: historias inventadas, historias con un germen de verdad envuelto en mentiras e historias súper partidistas (Janera y Pérez, 2017) y (PSOE, 2017), aunque a veces una noticia puede pertenecer a dos o incluso a los tres grupos. En el entorno político siempre son todas partidistas, siempre refuerzan las creencias ideológicas previas, tanto para creer la noticia como para no creerla. Y sean completamente falsas o basadas en una medio verdad tienen que ser creíbles para el público objetivo. Veamos en el siguiente gráfico qué tipos de partidos hacen uso de las diferentes categorías narrativas que engloban la posverdad. 

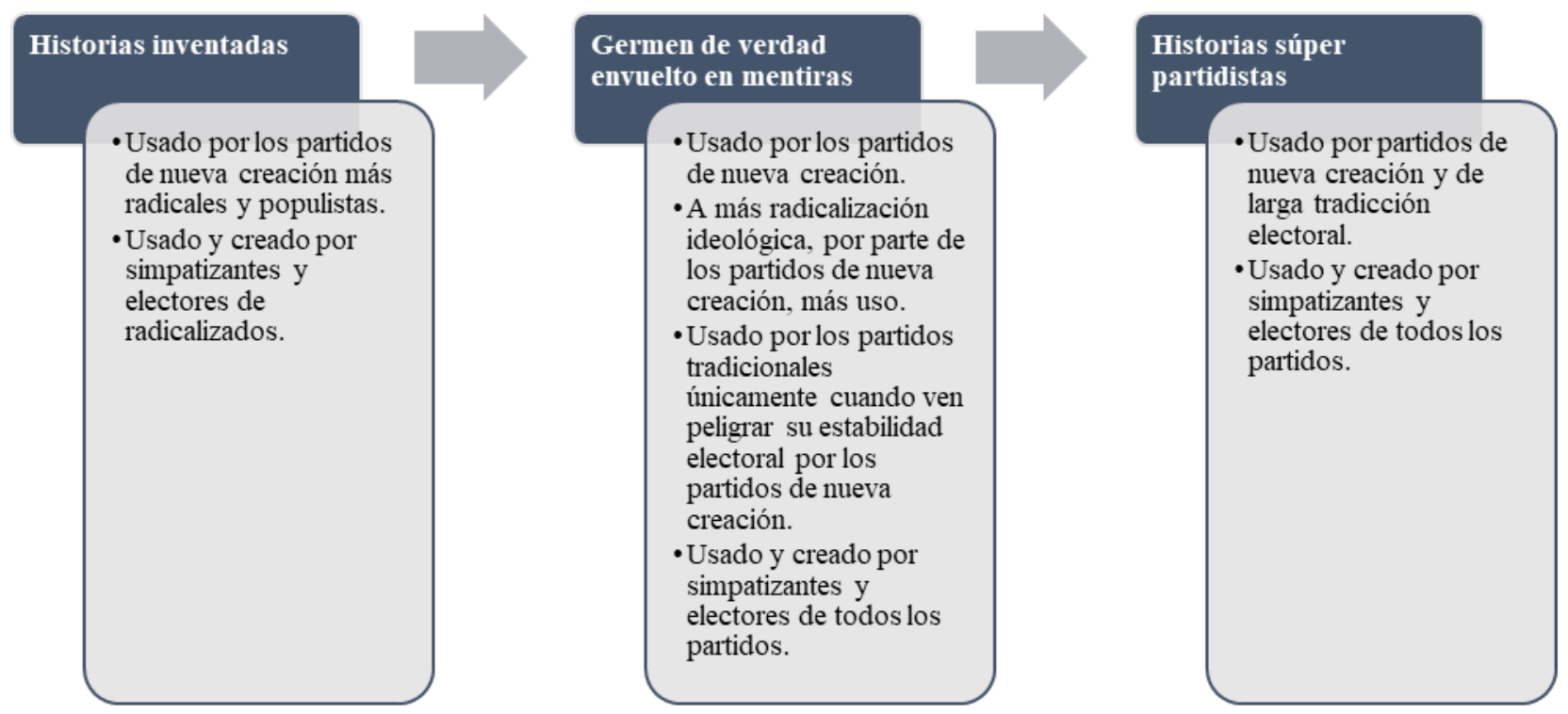

Figura 4. Uso de las categorías de la posverdad en España según la tipología de partido. Elaboración propia, 2021.

Y ¿por qué se producen estas noticias falas? Según Moya (2019) En las redes sociales da igual tu profesión, tu nivel económico o social, en las redes sociales se escucha a todos por igual y todos, pueden decir lo que quieran. Somos receptores y creadores de información al mismo tiempo. No es necesario basarse en una fuente para difundir cualquier información. Fotos, vídeos, blogs, etc., todo puede servir.

En definitiva, la era del prosumidor, "usuario proactivo, que es el creador y controlador de principio a fin de todo el contenido que genera. No solo es desarrollador, sino también estratega en ¿cómo? y ¿cuándo?, lanzar su contenido y mensaje para su mayor difusión y beneficio. Aquí la calidad es fundamental, por encima de la cantidad" (Moya, 2019, p. 34).

A su vez, los usuarios ejercen de transmisores de la actualidad que no conocen de filtros ni de sesgos ideológicos. Estos son los efectos del éxito del social media en convertir a un usuario pasivo, propio de los comienzos de Internet, en un usuario proactivo, el de hoy día. Los prosumidores que co-crean el marketing político 3.0 generando cambios en la dimensión político social.

Y esto quita poder al antes llamado cuarto poder, la prensa, ya que el modelo de negocio basado en la generación de contenidos y anuncios publicitarios se transforma en el desarrollo de nuevas aplicaciones que pudieran aprovechar dos de los grandes beneficios de Internet: conexión a cualquier hora y con cualquier parte del mundo, millones de ciudadanos en todo el mundo con la posibilidad de crear y difundir noticias. Y estos beneficios permiten que los lectores se conviertan en periodistas, que los ciudadanos sean los reporteros, que las noticias se co-creen. Pero este hecho puede tener, y ha tenido, una parte negativa, debido a que en los desarrollos web 2.0 no se contempla la figura del editor, moderador o intermediario entre los contenidos y la publicación de los mismos. Por lo que, si la noticia es falsa, nadie la contrasta. Y además el anonimato que permite la difusión de noticias en la red facilita la creación y propagación de noticias falsas.

Aunque muchas veces los autores están identificados son los propios partidos políticos o sus seguidores lo que crean y difunden sus posverdades. Buscan estar presentes en los votantes y para ello necesitan la viralización de los mensajes, y nada como un buen titular, una foto o vídeo para lograrlo 
No cabe ninguna duda de que el uso de la posverdad presente en los diferentes materiales de VOX: memes, vídeos, noticias y mensajes es de gran intensidad ya que son conscientes del gran impacto que generan. Podemos también ha usado la posverdad en muchas ocasiones.

En paralelo están los mensajes creados si un autor identificado, generalmente usando plataformas creadas para este fin y apoyándose en redes sociales, tales como Facebook, Youtube y WhastApp como las más usadas en España.

Por ejemplo y según publicó El País en octubre del 2020 “cientos de miles de españoles han leído que Albert Rivera quiere recuperar la mili para ninis, que el PP no quiere obreros en la universidad o que Podemos pretende prohibir las procesiones para no ofender a los musulmanes". Las tres noticias tienen dos cosas en común: tuvieron un enorme éxito en Facebook y son falsas.

En un artículo escrito por Kiko Llaneras en El País el 28 de enero del 2017, Mediterráneo Digital publicó que Podemos pretende prohibir las procesiones para no ofender a los musulmanes y obtuvo 120.000 interacciones en Facebook. La fuente era un tuit de una cuenta de Twitter presuntamente vinculada a Podemos que ya no existe. Un posible bot.

El mismo medio también publicó que "rumanos, ecuatorianos y marroquíes se comen siete de cada 10 euros de nuestra sanidad pública", lo que provocó 90.000 interacciones en Facebook. La noticia empieza con una rara promesa de fiabilidad: "Según un informe confidencial de Tribunal de Cuentas al que ha tenido acceso, en exclusiva, Mediterráneo Digital". En el mismo texto se reconoce que esos 7 de cada 10 euros son del presunto dinero destinado a inmigrantes, no de toda la sanidad pública española.

Es decir, se produce una manipulación del mensaje en cuanto que se transmiten verdades segmentadas o medias verdades, que junto con la interpretación popular van transformándose para convertirse en algunas ocasiones, en tema de debate público por lo impactante del hecho narrado.

Según el Consejo General de la Abogacía Española de 19 noviembre de 2020, España es uno de los países de la UE que padece un mayor número de noticias falsas, el $83 \%$ de los españoles asegura que se encuentra a menudo en Internet con fake news mientras que la media europea está en el 69\%. Entre otros motivos, en España, según el estudio de la Asociación para la Investigación de Medios de Comunicación (AIMC) de diciembre del 2020, tras la televisión (con un consumo medio de 212 minutos diarios), se encuentra Internet (con un consumo medio diario de 161 minutos).

Las redes sociales son el medio por el que más noticias falsas circulan a lo largo del día y en el que 26 millones de ciudadanos, el 87\% de los internautas entre 16 y 65 años, se declaran usuarios habituales, según un informe de la asociación de publicidad, marketing y comunicación digital IAB Spain de diciembre de 2020.

Las medidas adoptadas por Twitter y Facebook, creando algoritmos para verificar noticias, no están dando los resultados deseados porque muchas informaciones escapan a estos filtros. Además, otras muchas fake news se difunden en aplicaciones de mensajería, como Whatsapp o Telegram lo de dificulta frenar su difusión.

Ante el aumento de las interacciones devenidas de la posverdad y su fakes news, parece que Podemos, Ciudadanos, VOX y el resto de los partidos han dado un paso más en la evolución del marketing político 3.0, decidiendo incluir el uso de la posverdad en sus estrategias políticas, lo que ha pervertido el modelo en sí mismo. En vez de usar las redes para la co-creación de partidos y la elaboración de mensajes ilusionantes, se han decidido por la construcción del enemigo común mediante utilizando las bases de la posverdad. Este es también un paso más allá de una de las bases del marketing político 1.0, la comunicación defensiva y negativa.

\section{CONCLUSIÓN}

El objetivo del presente artículo ha sido demostrar que con la llegada de los nuevos partidos políticos (Podemos y Ciudadanos) a las instituciones españolas se sobrevino una nueva forma de hacer política, centrada en el uso del marketing político 3.0. Una forma de conectar con el 
electorado más efectiva, centrada en la co-creacción y en el prosumidor, aumentando la permeabilidad de las nuevas marcas políticas en el mercado electoral. Esta nueva forma de comunicar se tradujo en un respaldo electoral sin precedentes para los nuevos partidos.

Con la llegada de VOX en 2018 el modelo del marketing político no sólo se consolidó, sino que se mejoró. Vox aprendió de los aciertos y de los errores de Podemos y Ciudadanos a lo que añadió las estrategias electorales que iban usando sus homónimos internacionales, véase Donald Trump, así como las nuevas aplicaciones del Big Data.

El resto de los partidos políticos españoles, con un largo recorrido electoral y beneficiarios del pseudo bipartidismo (basado en la alternancia en el poder entre PSOE y PP), vieron que ya no solo tenían que combatir con su adversario ideológico, sino que desde el año 2016 también debían luchar contra aquellos nuevos partidos que se disputaban el mismo nicho de mercado.

El miedo a la fragmentación del voto, por parte de los partidos tradicionales, y a los futuros gobiernos de coalición, les hizo evolucionar del marketing 1.0 al 3.0 para poder tener la misma penetración en el mercado. La línea divisoria entre partidos ganadores y perdedores había desaparecido. Los poderes de la co-creación y el del prosumidor eran imparables e incalculables. A los partidos tradicionales no les quedó otra que reconocer como indispensables las herramientas del marketing 3.0.

Pero el modelo no se consolidó en su vertiente más purista, fue pervertido mediante el uso de las narrativas de la posverdad algo necesario en la psicopolítica que como dice Han (2017) "es aquel sistema de dominación que, en lugar de emplear el sistema opresor, utiliza un poder seductor, inteligente (Smart), que consigue que los hombres se sometan por sí mismos al entramado de dominación". Para lograrlo es necesario hacerlo apelando a la emoción y no a la razón, con mensajes hiperbólicos, desmesurados y en ocasiones falsos, recreados o inventados.

Y mientras todo esto sucede, el ciudadano como decía Han "se somete al entramado del poder consumiendo y comunicándose, incluso haciendo clic en el botón de me gusta" (2017, p. 30), posicionando al elector en una interactuación continua y multidireccional que favorece y refuerza al partido. Un partido que está en una campaña electoral constantemente.

El estudio verifica nuestras tres hipótesis: (1) Los partidos políticos de nueva creación: Podemos, Ciudadanos y Vox, consolidaron el modelo del marketing 3.0 en cuanto que eran los nativos del modelo y según fueron creciendo y afianzando su presencia a nivel institucional se dieron cuenta gran poder que tenían esas herramientas para seguir conectando con sus seguidores, lo que genero un cambio en la forma de hacer política en España. (2) Los partidos políticos de vieja tradición, asumieron que era necesario hacer uso de las estrategias del marketing 3.0 para conectar con un público que no podría ser filiado de otro modo, lo que les llevó a sumar más estrategias de marketing a las habituales. (3) La consolidación del modelo marketing político 3.0 ha llegado de la mano de narrativas propias de la posverdad que no han generado la construcción de un nuevo modelo sino perversión del 3.0, en cuanto que usa sus mismas herramientas, pero de manera distópica para la construcción de enemigos.

De las tres hipótesis, es la tercera que la que refiere un mayor impacto a nivel socio político en cuanto que el uso de las narrativas de la posverdad: historias inventadas, historias con un germen de verdad envuelto en mentiras e historias súper partidistas, siempre van cargadas de un contenido diferenciador y exacerbado con la intención de generar discordancias. Los partidos políticos se alejan cada vez más del entendimiento y del dialogo. Como decía Ibáñez (2017), una lucha por hegemonía política que ha llevado a cambiar las formas de hacer política. La posverdad les ha servido a los partidos para repensar la práctica política. El resultado polarización, radicalización y enemigos invisibles. 


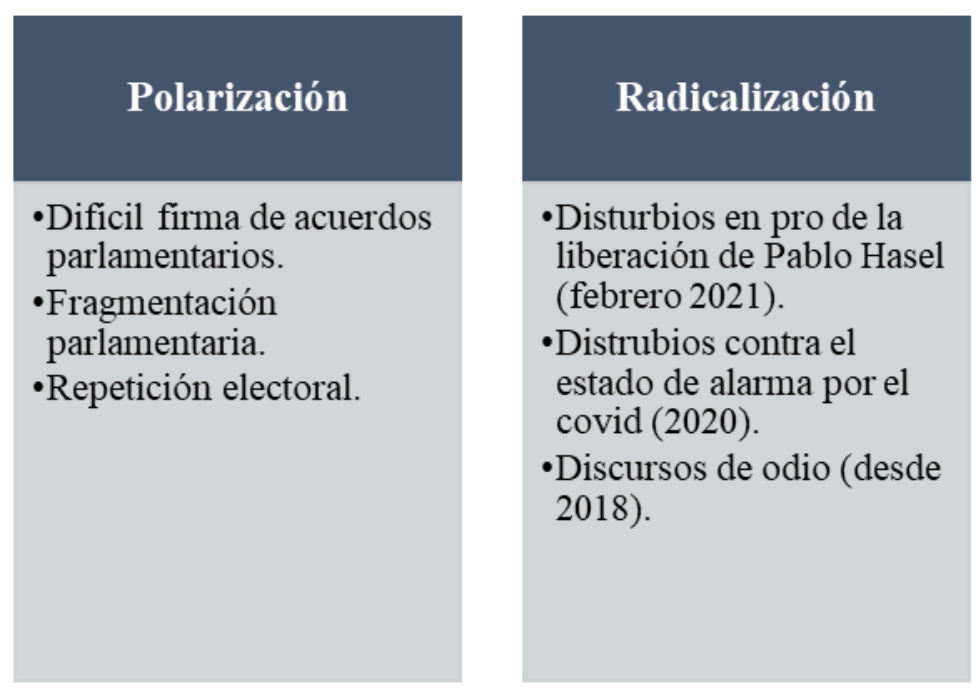

Enemigos invisibles

Figura 5. Consecuencias de la posverdad en la sociedad española. Ejemplos. Elaboración propia, 2021.

La polarización es evidente, el panorama político español actual está construido sobre un discurso de blancos y negros, no caben los grises. El dialogo cada vez se torna más complejo y la crispación cada vez registra niveles más altos. Esta crispación extrema aún más el posicionamiento de una parte del electorado, cada vez más desilusionada con lo político.

Y si a todo esto sumamos la brecha social, la pandemia, la crisis económica, la pérdida de empleo y el aumento de la vulnerabilidad social; resulta muy sencillo que los ciudadanos caigan presos de proclamas emocionales en las que se identifica a un colectivo como el causante de nuestros males.

La construcción del enemigo, tan dañina para las minorías, y tan utilizada por los partidos políticos, resulta actuar como anestésico de males. Es decir, una vez que el ciudadano se cree que "ese" es el culpable de sus males hará todo lo posible por resarcirse y ahí es cuando el problema adquiere unas dimensiones incontrolables. Puede adoptar la forma de revueltas, saqueos, disturbios, terrorismos urbanos, movilizaciones, etc.

Pero como venimos avisando no todos los partidos difunden estos mensajes con la misma intensidad, la magnitud y el radicalismo de los mismos depende del público que el partido político esté dispuesto a captar, siendo consciente que atraer a un determinado electorado siempre les podría fagocitar.

Dos son las limitaciones del estudio que aquí se presenta: 1) la pandemia, en cuanto que ha podido actuar como activador del uso de la posverdad, dentro de los partidos políticos, con el fin de obtener mayores réditos de la crisis, 2) la imposibilidad, también derivadas de la pandemia, de realizar unas entrevistas a representantes políticos. Primero porque estaban centrados en dar respuesta a los problemas pandémicos y en segundo lugar, porque las políticas de distanciamiento social, seguridad y prevención lo dificultaron.

Quizá, de no haberse producido la pandemia, se hubiese atisbado el uso de la posverdad dentro del marketing político 3.0 pero de una forma menos continuada. Y tal vez, el haber realizado una última ronda de entrevistas nos hubiese permitido entender en qué medida el uso de la posverdad por parte de los partidos políticos forma parte de las acciones comunicativas per sé.

Una pregunta nos surge como una posible línea de investigación futura ¿acaso los nuevos partidos podrán acabar con los tradicionalistas o serán estos los que los vuelvan agrupar el voto mayoritario antes un electorado cansado de la distopía?

Por último, indicar que la metodología de trabajo cualitativa propia de este trabajo puede ser aplicada a cualquier otro estudio de las Ciencias Sociales en el que se busque un estudio más en 
profundidad del problema. Por ejemplo, en el Grupo de Conocimiento e Investigación en Problemáticas Sociales, del que es Investigadora Principal la primera autora del artículo, el uso de la etnografía digital y física es el punto fuerte de sus estudios. Centrados en el ocio nocturno y las aplicaciones afectivo sexuales se mide la percepción del riesgo y de la vulnerabilidad de los usuarios. $^{17}$

\footnotetext{
${ }^{17}$ Para ampliar Información se recomienda leer: Silva, A., Cordero, R. R., Pérez, J. R., \& Briggs, D. (2019). Observing participants: digital ethnography in online dating environments and the cultivation of online research identities. Journal of Extreme Anthropology, vol. 3, no 1, pp. 135-151; Silva, A., Pérez, J. R., Cordero, R. R., \& Briggs, D. (2018). Mascarada cyborg. Etnografía digital aplicada a aplicaciones informáticas afectivo-sexuales. e-Eguzkilore. Zientzia Kriminologikoen Aldizkari Elektronikoa/Revista Electrónica de Ciencias Criminológicas, no 3, pp. 1-36; y Briggs, D., Cordero, R. R., Siva, A., y Pérez, J. R. (2019). "Las conductas de riesgo y la delincuencia en espacios turísticos de ocio nocturno". Sociología del turismo. Madrid: Centro de Investigaciones Sociológicas.
} 


\section{REFERENCIAS}

Anduiza, E., Crespo, I., y Méndez, M. (2009). Metodología de la ciencia política. Madrid: CIS.

Angrosino, M. (2012). Etnografía y observación participante en investigación cualitativa. Madrid: Ediciones Morata.

Aparici, R. y García. D. (2019). La posverdad: Una cartografía de los medios, las redes y la política. Barcelona: Gedisa.

Arroyo, L. (2012). El poder político en escena. Barcelona: RBA Libros.

Caldevilla, D. (2009). "Democracia 2.0: La política se introduce en las redes sociales. Pensar la Publicidad". Revista Internacional de Investigaciones Publicitarias, 3(2), 31-48.

Cárdenas, J. D. (2013). "Storytelling y márquetin político: Humanidad y emociones". Poliantea, 9 (16), p. 33-50.

Cordero R. y Reyero. L. (2020). Marketing político 3.0: cómo Podemos, Ciudadanos y Vox han cambiado las reglas del juego. Madrid: Tecnos.

Cordero, R., Vargas, J. J. y Reyero, L. (2017) “Aplicación y evolución de la investigación de mercados en el marketing político". Senderos de Historia Cultural. Venezuela: Universidad Metropolitana, p. 355-393.

Dvoskin, R. (2004). Fundamentos de marketing: Teoría y experiencia. Caba: Ediciones Granica.

González, A. (2018). «Postverdad y postverdad». Perifèria. Cristianisme, postmodernitat, globalització, [en línia]. Vol. 5, Núm. 5 , https://www.raco.cat/index.php/PeriferiaCPG/ article/view/342944 [Consulta: 25-02-2021].

Han, B. (2017). Psicopolítica. Barcelona: Herder.

Ibáñez, J. (2017). En la Era de la Posverdad. 14 ensayos. Valencia: Calambur.

Kotler, P., Kartajaya, H., y Setiawan, I. (2012). Marketing 3.0: Desvela cómo las empresas más influyentes atraen a sus clientes a través de un marketing basado en valores. Madrid: LID Editorial.

Kotler, P., y Roberto, E. L. (1992). Marketing social: Estrategias para cambiar la conducta pública. Madrid: Ediciones Díaz de Santos.

Llaneras, K., y Pérez, C. (2017). España también tiene noticias falsas. El país: https://elpais.com/politica/2017/01/27/actualid ad/1485523499 326784.html [Consulta: 0102-2021].
Maerek, P.J. (2009). Marketing político y comunicación. Claves para uma buena Información política. Barcelona: Paidós.

Mauser, A. (1983). Political marketing: An approach to campaign strategy. New York: Praeger.

Moya, E. (2018). "Redes Sociales Y Posverdad en el Devenir de los Estados". Cuadernos de estratégia. $\quad N^{o}$ 197, p. 107-158. https://dialnet.unirioja.es/descarga/articulo/65 18647.pdf [Consulta: 25-02-2021].

Pinchard, P. (2013). "Comunicación política en un mundo global: Una aplicación de marketing político". Communication policy in a global world: An application of political marketing. Revista Universitaria Ruta, 15(1), 29-48.

Reyero, L. (2017). La aplicación del Marketing Político 3.0. El caso del éxito de podemos y ciudadanos en las elecciones de 2014,2015 y 2016 [Tesis doctoral, Programa de Doctorado en Economía y Empresa, Universidad Europea de Madrid, España]. https://abacus.universidadeuropea.es/handle/1 1268/6985?show=full [Consulta: 25-02-2021].

Rodríguez-Ferrándiz, R. (2019). "Posverdad y fake news en comunicación política: breve genealogía". El profesional de la información, V. 28, $\quad$ n. 3 . https://doi.org/10.3145/epi.2019.may.14

Rodriguez, G., Gil, J. Y Garcia, E. (1996). Metodología de la investigación cualitativa. Málaga: Algibe.

Taylor, S. J., y Bogdan, R. (1987). Introducción a los métodos cualitativos de investigación. México: Paidós.

\section{WEBGRAFÍA}

Asociación para la Investigación de Medios de Comunicación (AIMC). https://www.aimc.es [Consulta: 20-02-2021].

IAB. Observatorio de la Publicidad Digital (datos diciembre 2020). https://iabspain.es [Consulta: 12-02-2021].

Oxford English Dictionary. https://www.oed.com [Consulta: 10-02-2021].

Partidos Socialista Obrero Español. http://web.psoe.es/zaragozalasfuentes/pressnot es/839866/page/espana-tambien-tienenoticias-falsas.html [Consulta: 05-02-2021].

Real Academia Española (ERA). https://www.rae.es/ [Consulta: 12-02-2021] 